\title{
PENGARUH MEDIA CD INTERAKTIF TERHADAP KETERAMPILAN BERPIKIR KREATIF SISWA DALAM MATA PELAJARAN IPS
}

\author{
Ading Muslihudin \\ adingmuslihudin85@gmail.com
}

\begin{abstract}
Permasalahan dalam penelitian ini adalah rendahnya keterampilan berpikir kreatif siswa dalam proses pembelajaran. Tujuan dari penelitian ini adalah untuk menguji pengaruh media CD interaktif dibandingkan dengan media konvensional terhadap keterampilan berpikir kreatif dalam mata pelajaran Ilmu Pengetahuan Sosial siswa kelas IV SD Negeri Cipicung Kabupaten Kuningan. Populasi dalam penelitian ini adalah seluruh siswa SD kelas IV di kecamatan cipicung dengan sampel penelitian siswa kelas IV SD Negeri Cipicung. Metode penelitian yang digunakan adalah kuasi eksperimen dengan desain Pretest Posttest Control Group Design. Alat tes penelitian ini adalah tes keterampilan berpikir kreatif. Data penelitian berupa tes dianalisis menggunakan program SPSS data pretes dan postest yang dianalisis secara kuantitatif dengan uji perbedaan dua rata-rata parametrik uji-t. Pengambilan sampel dilakukan dengan teknik purposive sampling. Hasil penelitian menunjukkan bahwa pembelajaran dengan menggunakan media CD interaktif mampu meningkatkan keterampilan berpikir kreatif siswa dalam mata pelajaran Ilmu Pengetahuan Sosial.
\end{abstract}

Kata Kunci : Media CD interaktif, Keterampilan berpikir kreatif 


\section{A. Pendahuluan}

Perkembangan teknologi informasi dan komunikasi (TIK) telah mengalami kemajuan yang sangat pesat bahkan telah merubah cara hidup umat manusia. Era informasi memberikan ruang lingkup yang sangat besar untuk mengorganisasikan segala kegiatan melalui cara baru, inovatif, instan, transfaran, akurat, serta lebih cepat, karena dengan teknologi informasi dan komunikasi seluruh proses kerja akan ditransformasikan dari fisik dan statis menjadi digital, mobile, virtual dan personal. Hampir semua sendi kehidupan umat manusia tidak terlepas dari sentuhan TIK, bahkan pada saat ini manusia akan mengalami kesulitan tanpa bantuan teknologi informasi dan komunikasi, termasuk dalam proses pembelajaran. Maka Sekolah sebagai agen perubahan (agent of changes) sudah sepatutnya menyesuaikan diri dengan perkembangan.

Keberadaan TIK merupakan suatu upaya untuk menjembatani masa sekarang dengan masa yang akan datang dengan jalan memperkenalkan pembaharuan-pembaharuan yang cenderung mengejar efisiensi dan efektivitas. Peradaban sebuah bangsa sangat ditentukan oleh tingkat penguasaan informasi dan komunikasi. Hingga saat ini sejarah membuktikan bahwa negara yang dikategorikan negara maju adalah negara-negara yang menguasai informasi dan komunikasi beserta teknologinya. Pada level individu, seseorang yang memiliki banyak informasi atau pengetahuan dan mampu mengkomunikasikannya dengan baik, akan menjadi orang yang penuh dinamis dan kreatif serta akan menjadi opinian leader di lingkungannya. (Suherman, 1997, hlm 1)

\section{Word Summit on the Information Society (WSIS) forum teknologi informasi dan komunikasi dunia di bawah badan Perserikatan Bangsa Bangsa (PBB) (Ahmadjayadi, 2009), sepakat untuk mencanangkan pada tahun 2015 rencana-rencana aksi sebagai berikut : \\ 1. Menghubungkan Desa dengan TIK dan membentuk Community Acces Point;}

2. Menghubungkan Universitas, Akademik, tingkat SMU dan SMP, tingkat SD dengan TIK;

3. Menghubungkan Pusat Ilmu dan Penelitian dengan TIK;

4. Menghubungkan Perpustakaan Umum, Pusat Kebudayaan, Museum, Kantor Pos dan Kearsipan dengan TIK;

5. Menghubungkan Pusat Kesehatan dan Rumah Sakit dengan TIK;

6. Menghubungkan seluruh instansi pemerintah pusat dan daerah dan membuat website dan alamat e-mail;

7. Mengadopsi seluruh kurikulum sekolah dasar dan menengah menghadapi tantangan maasyarakat informasi, harus diperhitungkan pada taraf internasional;

8. Memastikan bahwa seluruh populasi di dunia mempunyai akses untuk pelayanan televisi dan radio;

9. Mendorong pengembangan konten dan menempatkan pada tempatnya kondisi secara teknis dalam rangka memfasilitasi keadaan terkini dan penggunaan semua bahasa di dunia Internet;

10. Memastikan bahwa lebih dari setengah penduduk dunia mempunyai akses dengan TIK.

Perkembangan dunia teknologi saat ini sangat pesat, khususnya di bidang teknologi informasi dan komunikasi. 
Jadi sudah merupakan keharusan untuk memanfaatkan teknologi informasi dan komunikasi tersebut dalam dunia pendidikan. (Sa'ud, 2008, hlm 182). Pemanfaatan teknologi informasi dan komunikasi diharapkan dapat memperkaya wawasan dan keilmuan, sehingga pada akhirnya dapat meningkatkan kualitas ataupun mutu pendidikan bangsa Indonesia. Dampak negatif dari perkembangan teknologi informasi dan komunikasi tidak dapat dihindari, namun hal ini perlu untuk diminimalkan. Dampak perkembangan teknologi informasi dan komunikasi yang canggih, sebenarnya sangat tergantung dari sikap masyarakat menyikapinya. Teknologi akan berdampak buruk apabila penggunanya mengakses teknologi hanya pada sisi yang tidak sesuai dengan nilai kultur ataupun norma agama, sebaliknya, manusia dapat memperolah banyak manfaat jika mengakses berbagai perkembangan informasi yang dapat menunjang studi atau pekerjaan, serta dapat mengikuti perkembangan ilmu pengetahuan dan teknologi. (Aie Deti Heryanti, 2009)

Trilling and Fadel (Maftuh, 2010) menyatakan bahwa untuk menghadapi tantangan pada abad ke-21 seseorang harus memiliki keterampilan sebagai berikut:

critical thinking and problem solving, 2) communicating and collaboration, 3) creative and innovation, 4) information literacy, 5) media literacy, 6) ICT literacy, 7) flexibility and adaptability, 8) initiative and accountability, 9) leadership and responsibility

Dalam dunia pendidikan tantangan pada abad ke-21 adalah menyiapkan generasi muda yang luwes, kreatif dan proaktif. Generasi muda perlu dibentuk agar terampil dalam memecahkan masalah, bijak dalam membuat keputusan, berpikir kreatif, dan mampu bekerja secara individu maupun dalam kelompok. Hal ini didasari bahwa sekedar mengetahui pengetahuan (knowing of knowledge) saja terbukti tidak cukup untuk dapat berhasil dalam menghadapi hidup dan kehidupan yang semakin kompleks dan dapat berubah dengan cepat (Warsono dan Hariyanto, 2012, hlm 1). Untuk menjawab tantangan dan harapan tersebut hanya dapat diwujudkan melalui suatu pendidikan yang memfasilitasi siswa untuk dapat mengembangkan potensi yang dimilikinya.

Pada konteks ini, pembelajaran IPS di sekolah memiliki tempat yang strategis dan penting. Sebagaimana termuat dalam Peraturan Menteri Pendidikan Nasional (Permendiknas) Nomor 22 Tahun 2006 Tentang Standar Isi, bahwa melalui mata pelajaran IPS, siswa diarahkan untuk dapat menjadi warga negara Indonesia yang demokratis dan bertanggung jawab, serta warga dunia yang cinta damai.

Lebih lanjut, dengan merujuk pada Permendiknas Nomor 22 Tahun 2006 mata pelajaran IPS bertujuan agar peserta didik memiliki kemampuan sebagai berikut :

1. Mengenal konsep-konsep yang berkaitan dengan kehidupan bermasyarakat yang dinamis;

2. Memiliki kemampuan dasar untuk berpikir logis dan kritis, rasa ingin tahu, inquiri, memcahkan masalah, dan keterampilan dalam kehidupan sosial;

3. Memiliki komitmen dan kesadaran terhadap nilai-nilai sosial dan kemanusiaan;

4. Memiliki kemampuan berkomunikasi, bekerjasama dan berkompetisi dalam masyarakat yang 
majemuk, di tingkat lokal, nasional dan global

Untuk mencapai maksud dan tujuan pembelajaran IPS itu, bertolak dari pendapat yang dikemukakan oleh Sapriya (2011, hlm 48) maka siswa perlu dibekali dengan empat dimensi program pendidikan IPS yang komprehensif, meliputi : (1) Dimensi pengetahuan (Knowledge), (2) Dimensi keterampilan (Skills), (3) Dimensi nilai dan sikap (Values and Attitudes), dan (4) Dimensi tindakan (Action).

Berdasarkan dimensi dan tujuan pembelajaran IPS yang tercantum di atas, maka pembelajaran IPS seharusnya tidak hanya menekankan penguasaan fakta-fakta pada tingkat rendah yang sangat berorientasi pada buku teks. Belajar IPS hendaknya memberdayakan siswa sehingga segala potensi kemampuannya baik pengetahuan, sikap, maupun keterampilanya dapat berkembang. Seluruh kemampuan tersebut dapat terwujud dalam proses pembelajaran dengan melibatkan parsitipasi belajar siswa secara sepenuhnya. Keterlibatan atau partisipasi peserta didik dalam belajar mengajar merupakan dasar pengembangan dan pelatihan bagi siswa untuk berpartisipasi dan bekerja sama dalam kehidupan bermasyarakat. Hal ini sesuai dengan yang dijelaskan oleh Jarolimek dan Parker (1993) bahwa "ujian yang sesungguhnya dalam bentuk belajar IPS terjadi ketika siswa berada di luar sekolah yakni hidup di masyarakat".

Pembelajaran IPS di Sekolah Dasar saat ini terkesan terpisah dari kehidupan nyata siswa, sehingga dirasakan kurang optimal diserap oleh siswa. Como dan Snow (Budi Herjanto, 2012, hlm 9), menilai bahwa model pembelajaran IPS yang diimplementasikan saat ini masih bersifat konvensional sehingga siswa sulit memperoleh pelayanan secara optimal. Selain itu, proses pembelajaran IPS belum memberikan kesempatan yang memadai kepada siswa untuk mengembangkan dimensi keterampilan yang mereka miliki. Padahal menurut Sapriya (2011, hlm 12), IPS di tingkat sekolah pada dasarnya bertujuan untuk mempersiapkan para siswa sebagai warga negara yang menguasai pengetahuan (knowledge), keterampilan (skill), sikap dan nilai (attitudes and values) yang dapat digunakan sebagai kemampuan untuk memecahkan masalah pribadi atau masalah sosial serta kemampuan mengambil keputusan dan berpartisipasi dalam berbagai kegiatan kemasyarakatan agar menjadi warga negara yang baik.

Menurut Soemantri (2001), proses pembelajaran IPS di tingkat persekolahan masih mengandung beberapa kelemahan, yaitu :

1. Kurang memperhatikan perubahanperubahan dalam tujuan, fungsi dan peran Pendidikan IPS di sekolah, tujuan pembelajan kurang jelas dan tidak tegas (not purposeful).

2. Posisi, peran dan hubungan fungsional dengan bidang studi lainnya terabaikan. Informasi faktual lebih bertumpu pada buku paket yang out of date dan kurang mendayagunakan sumber-sumber lainnya.

3. Lemahnya transfer informasi konsep ilmu-ilmu sosial out put Pendidikan IPS tidak memberikan tambahan daya dan tidak pula mengandung kekuatan (not empowering and not powerful).

4. Guru tidak dapat meyakinkan siswa untuk belajar Pendidikan IPS lebih begairah dan bersungguh-sungguh. Siswa tidak dibelajarkan untuk membangun konseptualisasi yang mandiri. 
5. Guru lebih mendominasi siswa (teacher centered). Kadang pembelajaran yang rendah, kebutuhan belajar siswa tidak terlayani.

6. Belum membiasakan pengalaman nilai-nilai kehidupan demokrasi sosial kemasyarakatan dengan melibatkan siswa dan seluruh komunitas sekolah dalam berbagai komunitas sekolah. Dalam pertemuan kelas tidak mengagendakan setting lokal, nasional dan global, khususnya berkaitan dengan struktur sistem sosial dan perilaku kemasyarakatan.

Berdasarkan hasil pengamatan awal mengenai proses belajar mengajar yang dilakukan di kelas IV SD Negeri Cipicung menunjukan bahwa keterampilan berpikir kreatif siswa masih belum dikembangkan secara maksimal. Dalam kegiatan evaluasi guru menuntut jawaban siswa sama persis seperti yang ia jelaskan. Dengan kata lain siswa tidak diberikan peluang untuk berpikir kreatif.

Ayan (Rachmawati dan Kurniati, 2011:36) hasil risetnya menunjukkan bahwa kreativitas mulai hilang pada masa kanak-kanak menuju masa dewasa. Salah satu kajiannya telah mencermati kemampuan individu dalam memunculkan ide orisinal, nilai perbandingan jawaban orisinal (unik) dan standar (biasa) yang dihasilkan adalah sebagai berikut:

Tabel 1

Tingkat orisinalitas berdasarkan usia

\begin{tabular}{|l|l|}
\hline Umur 5 atau kurang & $90 \%$ orisinil \\
\hline Umur 7 & $20 \%$ orisinil \\
\hline Orang dewasa & $2 \%$ orisinil \\
\hline
\end{tabular}

Hilangnya orisinalitas ini sangat mengejutkan. Tidak heran jika banyak orang dewasa cepat merasa kecewa dan menyerah ketika mencoba melakukan perubahan, pembaharuan dan produk kreatif lainnya. Oleh karena itu diperlukan adanya program-program pembelajaran yang akan tetap memelihara potensi kreatif anak. Pentingnya mengembangkan keterampilan berpikir kreatif pada diri siswa dikemukakan oleh Munandar (2012, hlm 31), sebagai berikut: Pertama, dengan berkreasi orang dapat mengaktualisasikan dirinya. Kedua, berpikir kreatif sebagai kemampuan untuk melihat bermacam-macam kemungkinan penyelesaian terhadap suatu masalah, merupakan bentuk pemikiran yang sampai saat ini masih kurang mendapat perhatian dalam pendidikan. Ketiga, bersibuk diri secara kreatif tidak hanya bermanfaat (bagi diri pribadi dan bagi lingkungan) tetapi juga memberikan kepuasan kepada individu. Keempat, kreativitaslah yang memungkinkan manusia meningkatkan kualitas hidupnya.

Sebagai ujung tombak dalam pendidikan, maka sangatlah penting bagi guru untuk memahami karakteristik materi siswa, metodologi dan media pembelajaran yang inovatif, sehingga proses pembelajaran akan menjadi lebih variatif, inovatif dan konstruktif serta dapat meningkatkan dan kreativitas siswa. Menurut Macaulay (Muhyidin, dkk, 2013, hlm 175) CD pembelajaran merupakan salah satu inovasi dari pembelajaran berbasis komputer. Menurut Bambang Warsita (Arif Mahya Fanny dan Siti Partini Suardiman, 2013, hlm 2) Dengan pembelajaran berbasis komputer, diharapkan dapat membantu pembelajaran yang memiliki kecepatan belajar lebih lambat (slow learner) agar dapat belajar secara efektif, karena dengan komputer untuk menanyangkan kembali informasi yang diperlukan, sedangkan bagi pembelajar yang lebih 
cepat (fast learner) dapat memaacu aktifitas belajar.

Dalam penelitian ini media pembelajaran yang dipilih adalah media CD interaktif yang diasumsikan dapat meningkatkan keterampilan berpikir kreatif dan motivasi belajar siswa. Hal ini berdasarkan hasil penelitian Ratri, Redjeki, \& Nugroho (2013, hlm 28) bahwa motivasi belajar siswa dapat ditingkatkan dengan menggunakan media atau model pembelajaran. Transfield (Feby Rizka Ayuning Wulandari, dkk,2013, hlm 264) Peningkatan kualitas pendidikan dan pengetahuan dapat dilakukan salah satunya dengan pembelajaran menggunakan CD interaktif. Menurut Arends (Karina, dkk, 2013, hlm 107), menyebutkan bahwa CD pembelajaran, simulasi, dan web-web virtual dapat digunakan sebagai media dalam penyampaian materi di kelas untuk meningkatkan motivasi atau minat siswa. Media CD interaktif adalah salah satu media interaktif yang bisa terbilang baru. CD interaktif memiliki beberapa keunggulan antara lain: (1) Penggunanya bisa berinteraksi dengan program komputer. (2) Menambah pengetahuan, (3) Tampilan audio visual yang menarik. Dari beberapa keunggulan CD interaktif, dapat diketahui bahwa $C D$ interaktif dapat membantu mempertajam pesan yang disampiakan dengan kelebihannya menarik indera dan menarik minat, karena merupakan gabungan antara pandangan, suara, dan gerakan, Suyatno (2004)

UNESCO 2002 (Sri Wardani, dkk, 2013, hlm 169) menyatakan bahwa penggunaan ICT dalam pembelajaran memiliki tiga tujuan, yaitu: 1) untuk membangun "knowledge-based society habits" seperti kemampuan pemecahan masalah (problem solving), kemampuan berkomunikasi,

kemampuan mencari/mengelola informasi, mengubah informasi tersebut menjadi pengetahuan baru dan menginformasikannya kepada orang lain, 2) untuk mengembangkan kemampuan menggunakan ICT atau "ICT literacy", dan 3) untuk meningkatkan efektifitas dan efisiensi proses pembelajaran.

kelebihan dan kekurangan dari CD interaktif adalah sebagai berikut:

a. Kelebihan

1) Pengguna (user) dapat berinteraksi dengan program komputer. Suyanto (Erni Suardani Ketut dkk, 2013, hlm 3)

2) Menambah pengetahuan. Pengetahuan yang dimaksud adalah materi yang disajikan dalam CD interaktif.

3) Tampilan audio visual yang menarik. Menarik di sini tentu saja jika dibandingkan dengan media konvensional seperti buku atau media lainnya. Kemenarikan dalam CD interaktif karena sistem interaksi yang tidak dimiliki oleh media cetak (buku) maupun media elektronik lain (TV, Radio).

4) Dengan CD interaktif dapat membantu mempertajam pesan yang disampaikan dengan kelebihannya menarik indera dan menarik minat, karena merupakan gabungan antara penglihatan, suara dan gerak.

b. Kekurangan

1) Medium yang dapat digunakan hanya komputer.

2) Membatasi target pengguna (user) karena hanya pemakai komputer saja yang dapat mengakses.

3) Pemeliharaannya harus hati-hati daripada buku agar tidak terkena 
panas, tergores atau pecah.

Taufiq Zulfikar (2011).

Berdasarkan studi literatur terhadap penelitian tentang media CD interaktif, ditemukan bahwa media CD interaktif secara signifikan dapat lebih meningkatkan pemahaman dan retensi siswa (Eddy Noviana, 2008). Wening Astuti (2011) menyatakan bahwa kemampuan berpikir kritis dan kreatif siswa SD meningkat setelah menggunakan multimedia matematika interaktif.

\section{B. Metode Penelitian}

Metode yang digunakan dalam penelitian ini adalah eksperimen kuasi dengan desain yang digunakan adalah desain "pretest-posttest control group design" (Sugiyono, 2009, hlm 113). Adapun populasi dalam penelitian ini adalah seluruh siswa SD kelas IV di kecamatan cipicung dengan sampel penelitian siswa kelas IV SD Negeri Cipicung. Kemudian dilakukan pretest terhadap ke dua kelompok, setelah itu kedua kelompok diberikan perlakuan yang berbeda dan diakhiri dengan pemberian posttest pada kedua kelompok. Untuk pretes dan posttest digunakan perangkat test yang sama. Rancangan desain penelitian dapat dilihat pada tabel di bawah ini:

\section{Tabel 2}

Desain Penelitian

\begin{tabular}{|l|c|c|c|}
\hline \multicolumn{1}{|c|}{ Kelompok } & Pretest & Perlakuan & Posttest \\
\hline Eksperimen & $\mathrm{O}_{1}$ & $\mathrm{X}$ & $\mathrm{O}_{2}$ \\
\hline Kontrol & $\mathrm{O}_{1}$ & - & $\mathrm{O}_{2}$ \\
\hline \multicolumn{4}{|c}{ (Sugiono, 2010, hlm } \\
& $116)$
\end{tabular}

Keterangan :

O1 $=$ Tes Awal (pretest)

$\mathrm{O} 2=$ Tes Akhir (posttest)

$\mathrm{X}=$ Media CD interaktif

\section{Hasil Penelitian}

Berdasarkan hasil pretes kemampuan berpikir kreatif diperoleh data uji normalitas Kolmogorov-Smirnov dengan bantuan SPSS 20 for windows seperti disajikan pada tabel berikut.

Tabel 3

Hasil Uji Normalitas Data

Pretes Keterampilan berpikir kreatif

\begin{tabular}{|l|c|c|c|}
\hline Kelas & $\begin{array}{c}\text { Kolmogorov- } \\
\text { Smirnov (sig) }\end{array}$ & $\boldsymbol{\alpha}$ & Kesimpulan \\
\hline Eksperimen & 0,068 & 0,05 & Normal \\
\hline Kontrol & 0,119 & 0,05 & Normal \\
\hline
\end{tabular}

Berdasarkan tabel di atas, nilai signifikansi skor pretes pada kelas eksperimen 0,068, lebih besar dari $\propto=0,05$, dan pada kelas kontrol 0,119, juga lebih besar dari $\propto=0,05$. Dengan memperhatikan kriteria pengujian, maka $\mathrm{H}_{0}$ diterima. Hal ini berarti pada tingkat kepercayaan 95\%, data pretes keterampilan berpikir kreatif siswa pada kelas eksperimen dan kelas kontrol berdistribusi normal.

Hasil pengolahan data uji homogenitas Levene's test dengan bantuan Software SPSS 20 disajikan pada tabel berikut.

Tabel 4

Hasil Uji Homogenitas Data Pretes Keterampilan berpikir kreatif

\begin{tabular}{|c|c|c|}
\hline $\begin{array}{c}\text { Levene's test } \\
\text { (sig) }\end{array}$ & $\boldsymbol{\alpha}$ & Kesimpulan \\
\hline 0,464 & 0,05 & Homogen \\
\hline
\end{tabular}

Berdasarkan tabel di atas, nilai signifikansi untuk data pretes keterampilan berpikir kreatif siswa adalah 0,464, lebih besar dari $\propto=$ 0,05 . Dengan memperhatikan kriteria pengujian, maka $\mathrm{H}_{0}$ diterima. Hal ini berarti pada tingkat kepercayaan 95\%, varians data pretes keterampilan berpikir kreatif siswa kedua kelas homogen.

Hasil pengolahan uji $\mathrm{t}$ independent sample test dengan bantuan 
Software SPSS 20 disajikan pada tabel berikut.

Tabel 5

Hasil Uji t Independent Sample Test Data Pretes

Kemampuan awal keterampilan berpikir kreatif

\begin{tabular}{|c|c|}
\hline $\begin{array}{c}\text { t } \text { independent } \\
\text { sample test }\end{array}$ & $\begin{array}{c}\text { N-Gain Keterampilan } \\
\text { berpikir kreatif }\end{array}$ \\
\hline Sig (2-tailed) & 0,685 \\
\hline Sig (1-tailed) & 0,3425 \\
\hline
\end{tabular}

Berdasarkan tabel di atas, nilai signifikansi 1-tailed uji $\mathrm{t}$ independent sample test data pretes kemampuan awal berpikir kritis siswa adalah 0,3425 , lebih besar dari $\propto=0,05$. Dengan memperhatikan kriteria pengujian di atas, maka $\mathrm{H}_{0}$ diterima. Dengan kata lain pada tingkat kepercayaan 95\%, tidak terdapat perbedaan rata-rata kemampuan awal berpikir kritis antara siswa yang akan mendapatkan pembelajaran media CD interaktif dengan siswa yang akan mendapatkan

konvensional.

Adapun berdasarkan data $\mathrm{N}$-gain (peningkatan keterampilan berpikir kreatif) diperoleh hasil uji normalitas data pada kedua kelas dapat dilihat dari hasil SPSS 20 yang disajikan pada tabel di bawah ini.

Tabel 6

Hasil Uji Normalitas Data N-Gain Keterampilan berpikir kreatif

\begin{tabular}{|l|c|c|c|}
\hline \multicolumn{1}{|c|}{ Kelas } & $\begin{array}{c}\text { Kolmogorov- } \\
\text { Smirnov } \\
(\mathbf{s i g})\end{array}$ & $\boldsymbol{\alpha}$ & Kesimpulan \\
\hline Eksperimen & 0,737 & 0,05 & Normal \\
\hline Kontrol & 0,098 & 0,05 & Normal \\
\hline
\end{tabular}

Berdasarkan tabel di atas, terlihat bahwa nilai signifikansi skor $\mathrm{N}$-gain pada kelas eksperimen sebesar 0,737, lebih besar dari $\propto=0,05$, sehingga dengan memperhatikan kriteria pengujian normalitas, maka $\mathrm{H}_{0}$ diterima. Adapun pada kelas kontrolnilai signifikansi skor $\mathrm{N}$-gainsebesar 0,098, lebih besar dari $\propto=0,05$ sehingga dengan memperhatikan kriteria pengujian normalitas, maka $\mathrm{H}_{0}$ diterima. Hal ini berarti pada tingkat kepercayaan $95 \%$, data $N$-gain keterampilan berpikir kreatif siswa pada kelas eksperimen dan kelas kontrol berdistribusi normal.

Hasil pengolahan data uji homogenitas dengan menggunakan Levene's testdengan bantuan SPSS 20 disajikan pada tabel berikut.

Tabel 7

Hasil Uji Homogenitas Levene's TestData N-Gain

Keterampilan berpikir kreatif

\begin{tabular}{|c|c|c|}
\hline $\begin{array}{c}\text { Levene's } \\
\text { test (sig) }\end{array}$ & $\boldsymbol{\alpha}$ & Kesimpulan \\
\hline 0,091 & 0,05 & Homogen \\
\hline
\end{tabular}

Berdasarkan tabel di atas, diperoleh nilai signifikansi Levene's testuntuk data $N$-gainketerampilan berpikir kreatifsiswa adalah 0,69 , lebih besar dari nilai $\propto=0,05$. Dengan demikian, berdasarkan kriteria pengujian homogenitas di atas, maka $\mathrm{H}_{0}$ diterima.Hal ini dapat disimpulkan bahwa pada tingkat kepercayaan 95\%, varians data $N$-gain keterampilan berpikir kreatif siswa pada kedua kelas adalah homogen.

Hasil pengolahan uji $\mathrm{t}$ independent sample test dengan bantuan SPSS 20 disajikan pada tabel berikut.

Tabel 8

Hasil Uji t Independent Sample Test Data N-Gain

Keterampilan berpikir kreatif

\begin{tabular}{|c|c|}
\hline $\begin{array}{c}\text { t independent } \\
\text { sample test }\end{array}$ & $\begin{array}{c}\text { N-GainKeterampilan } \\
\text { berpikir kreatif }\end{array}$ \\
\hline Sig (2-tailed) & 0,001 \\
\hline Sig (1-tailed) & 0,0005 \\
\hline
\end{tabular}

Berdasarkan tabel di atas, nilai signifikansi 1-tailed uji $\mathrm{t}$ independent 
sample test data $N$-gain keterampilan berpikir kreatif siswa adalah sebesar 0,0005 dan lebih kecil dari nilai $\propto=0,05$ sehingga berdasarkan kriteria pengujian, maka $\mathrm{H}_{0}$ ditolak. Dengan kata lain, secara signifikan rata-rata $N$ gain keterampilan berpikir kreatif siswa yang mendapatkan pembelajaran media CD interaktif lebih tinggi daripada siswa yang mendapatkan pembelajaran konvensional. Hal ini berarti pada tingkat kepercayaan $95 \%$, peningkatan keterampilan berpikir kreatif siswa yang mendapatkan pembelajaran media CD interaktif lebih baik daripada siswa yang mendapatkan

konvensional.

\section{Kesimpulan}

Berdasarkan hasil penelitian dan pembahasan pada bagian terdahulu mengenai keterampilan berpikir kreatif dan motivasi belajar siswa melalui pembelajaran menggunakan media $\mathrm{CD}$ interaktif, diperoleh kesimpulan sebagai berikut:

1. Terdapat perbedaan keterampilan berpikir kreatif siswa antara pengukuran awal dengan pengukuran akhir pada kelas eksperimen yang menggunakan media CD interaktif.

2. Terdapat perbedaan peningkatan keterampilan berpikir kreatif siswa dalam pembelajaran IPS antara kelas eksperimen yang menggunakan media CD interaktif dan kelas kontrol yang menerapkan media konvensional. Dengan demikian berarti keterampilan berpikir kreatif siswa yang menggunakan media CD interaktif pada kelas eksperimen mengalami peningkatan keterampilan berpikir kreatif yang lebih baik dibandingkan dengan siswa yang menggunakan media konvensional pada kelas kontrol.

\section{E. Daftar Pustaka}

Abidin, Z., \& Saputro, T. M. E. (2008). Upaya meningkatkan motivasi dan pemahaman siswa pada materi geometri dan pengukuran melalui kegiatan "remase" di smp 33 semarang. Jurnal Kreano2 (2), hlm. 133-141.

Agustinawati, S, \& Nugroho, G.K. (2013). Pembuatan media pembelajaran icrosoft excel pada sekolah menengah pertama negeri 2 tawangmangu. Journal Speed Sentra Penelitian Engineering dan Edukasi - Volume 5 No 4, hlm 66-72

Anasari, T. (2009). Membuat media pembelajaran pembuatan blog berbasis multimedia pada smk negeri 1 gondang sragen Journal Speed - Sentra Penelitian Engineering dan Edukasi Volume 1 No 3, hlm 58-66

Arifin, Z. (2012). Evaluasi pembelajaran. Jakarta. Direktorat Jenderal Pendidikan Islam Kementerian Agama.

Arikunto, S. ( 2012). Dasar-dasar evaluasi pendidikan. Jakarta: Bumi aksara

Azhar Arsyad. (2011). Media pembelajaran. Jakarta: PT Raja Grafindo Persada.

Aziz, a Saefudin. (2012). Pengembangan kemampuan berpikir kreatif siswa dalam pembelajaran matematika dengan pendekatan pendidikan matematika realistik 
indonesia (PMRI) Al-Bidāyah, Vol 4 No. 1, hlm 37-49

Azizah, M, Rustiana, A \& Pramusinto, H. (2012). Penerapan model pembelajaran group investigation untuk meningkatkan kreativitas siswa pada pelajaran produktif. Economic Education Analysis Journal 1 (1), hlm 1-7

Bates, A.W.T. (1995). Technology open learning and distance education. New York.: TJ Press Ltd

Binuko, H. (2010). Pengembangan cd interaktif bimbingan belajar pada siswa kelas vii di smpn 5 sleman. Skripsi tidak diterbitkan. FIP UNY.

Dimyati \& Mudjiono. (1999). Belajar dan pembelajaran. Bandung. Rineka Cipta

Ditti, W. (2002). Multimedia dalam misrosoft encarta encyclopedia. Washington D.C.: Microsoft

Djaihari, A.K. (1996). Dasar-dasar umum metodelogi pengajaran nilai moral pcvt. Bandung

Eddy, N. (2008). Penggunaan teknologi multimedia interaktif dalam pembelajaran ilmu pengetahuan sosial untuk meningkatkan pemahaman dan retensi siswa. Tesis PPs UPI. Bandung; tidak dipublikasikan

Fanny, A.M \& Suardiman, S.P. (2013). Pengembangan multimedia interaktif untuk mata pelajaran ilmu pengetahuan sosial (ips) sekolah dasar kelas v. Jurnal Prima Edukasia 1 (1), hlm 1 -9
Filsaime, D.K (2008). Menguak rahasia berpikir kreatif dan kreatif. Jakarta: Prestasi Pustaka

Gesang, Y.W, \& Nugoho, K. (2014). Pembangunan media pembelajaran alat transportasi dan rambu-rambu lalu lintas pada taman kanak-kanak pertiwi 1 plumbungan karangmalang sragen. Journal Speed - Sentra Penelitian Engineering dan Edukasi - Volume 6 No 2 - 2014, hlm 40-45

Gunawan, R. (2011). Pendidikan ips filosofi, konsep dan aplikasi. Bandung: Alfabeta

Hamalik, O. (2003). Proses belajar mengajar. Jakarta. Bumi Aksara

Hendraningrat,R.W, \& Urbani, Y.H. (2014). Produksi video klip multiplek lagu "semalam di cianjur" berbasis multimedia. Journal Speed - Sentra Penelitian Engineering dan Edukasi Volume 6 No 4, hlm 51-58

Herijanto, B. (2012). Pengembangan cd interaktif pembelajaran ips materi bencana alam. Journal of Educational Social Studies 1 (1), hlm 8-12

Heryanti, A.D. (2009). Belajar mandiri berbasis teknologi multimedia, Pikiran Rakyat, Senin 12 Oktober 2009

Janzuli, I. (2015). Media pembelajaran interaktif listrik dinamis smk wisudha karya kudus pada kelas x. Journal Speed - Sentra Penelitian Engineering dan 
Edukasi - Volume 7 No 1, hlm 65-69

Latifah, F. \& Triyono, R.A. (2014). Media pembelajaran interaktif induksi elektromagnetik di smp muhammadiyah 1 kudus pada kelas 8 Journal Speed - Sentra Penelitian Engineering dan Edukasi - Volume 6 No 4, hlm 711

Mardani, A \& Tjendrowasono, T.I. (2012). Pembuatan media pembelajaran interaktif keterampilan komputer dan pengelolaan informasi untuk sekolah menengah kejuruan kelas xi Journal Speed - Sentra Penelitian Engineering dan Edukasi - Volume 4 No 2, hlm 46-51

Muhyidin, Dwijanto \& Masrukan. (2013). Pembelajaran dengan model kontruktivisme berbasis matematika realistic berbantu cd pembelajaran kelas IV. Journal of Primary Education 2 (1), hlm 174-179

Mulyasa, E.(2006). Menjadi guru profesional menciptakan pembelajaran kreatif dan menyenangkan Bandung: Remaja Rosdakarya offset

Munandar, U. (2012). Pengembangan kreativitas anak berbakat. Jakarta : PT Rineka Cipta

Munir. (2001) Aplikasi teknologi multimedia dalam proses belajar mengajar: Mimbar Pendidikan No 3 Tahun XX

Mustaqim.(2000). Psikologi pendidikan.

\section{Yogyakarta. Pustaka Pelajar}

Nasution, S. (1990). Asas-asas kurikulum. Bandung. Jemmars

Nurizzati, Y. (2012). Upaya mengembangkan kemampuan berpikir kritis dan kreatif mahasiswa ips. Jurnal Edueksos Vol I No 2, hlm 93-108

Nurryna, A.F. (2009). Pengembangan media pendidikan untuk inovasi pembelajaran. Journal Speed Sentra Penelitian Engineering dan Edukasi - Volume 1 No 2, hlm 1-5

Oktaviani, H.I. (2014). Peningkatan kemampuan berpikir kritis dan kreatif siswa melalui model pemerolehan konsep Jurnal Pendidikan Humaniora Vol. 2 No. 3, Hlm 263-272

Palupi, D.A.R. (2015). Media pembelajaran interaktif microsoft excel 2003 sekolah dasar negeri 01 sukosari Journal SpeedSentra Penelitian Engineering dan Edukasi - Volume 11 No 3, hlm 50-58

Peraturan Menteri Pendidikan Nasional Republik Indonesia Nomor 22 tahun 2006

Pratinuari, K, Sugiarto, \& Pujiastuti, E. (2013). Keefektifan pendekatan open-ended dengan pembelajaran kontekstual terhadap kemampuan berpikir kreatif Unnes journal of mathematic education UJME 2 (1), hlm 105-113

Rachmawati, Y \& kurniati, E. (2011). Strategi pengembangan 
kreativitas pada anak usia taman kanak-kanak. Jakarta: Kencana

Ridwan. (2003). Dasar-dasar statistika. Bandung. Alfabeta.

Rinjani, N.M.A.G, Candiasa, I.M, \& Koyan, I.W. (2013). Pengembangan cd interaktif pembelajaran statistik dengan mengaplikasikan spss (statistical package for social science) sebagai pengolah data. e-Journal Program Pascasarjana Universitas Pendidikan Ganesha Program Studi Penelitian dan Evaluasi Pendidikan (Volume 3), hlm 1-11

Rohman. (2012). Media pembelajaran studio pinnacle berbasis multimedia. Journal Speed Sentra Penelitian Engineering dan Edukasi - Volume 4 No 3, hlm 32-38

Ruseffendi. (2006). Dasar-dasar penelitian pendidikan dan bidang non eksakta lainnya. Semarang:IKIP Press.

Sa'ud, U.S. (2006). Inovasi pendidikan.Bandung: UPI Press

Sanaky, H. (2011). Media pembelajaran. Yogyakarta: Kaukaba Dipantara.

Santoso, A.B. (2014). Keeftifan pembelajaran mengunakan media cd pembelajaran pada mata pelajaran pada mata pelajaran ips kelas v sd Jurnal Ilmiah Mitra Swara Ganesha, Vol. 1 No. 1, hlm 19-36

Sapriya (2007). Pengembangan pendidikan ips di sd. UPI Press

Sapriya. (2011). Pendidikan ips konsep dan pembelajaran. Bandung: Rosdakarya.

Sugiyono. (2011). Statistika untuk penelitian. Bandung. Alfabeta.

Supriadi, D. (2001). Bermain kreatif berbasis kecerdasan jamak. Jakarta: PT. Indeks

Supriatna, N, dkk. (2007). Pendidikan ips di sd. Bandung: UPI Press

Susilana \& Riyana. (2008). Media pembelajaran (hakikat, pengembangan, pemanfaatan dan penilaian). Bandung: FIP UPI

Susetyo, B. (2012). Statistika untuk analisis data penelitian. Bandung. Refika Aditama.

Syaodih, N. (2013). Metode penelitian pendidikan. Bandung. PT Remaja Rosdakarya.

Utami, H.W. (2014). Efektivitas pembelajaran kooperatif model think-pairsquare berbantuan video pembelajaran dalam meningkatan kreativitas siswa pada kompetensi dasar laporan keuangan Economic Education Analysis Journal EEAJ 2 (3), hlm 60-67

Wardani, S, Mudzalipah, I, \& Hidayat. E. (2013). Pengembangan media pembelajaran berbasis multimedia interaktif untuk memfasilitasi belajar mandiri mahasiswa pada mata kuliah kapita selekta 
matematika. Jurnal Pengajaran MIPA, Volume 18, Nomor 2, hlm. 167-177

Warsita, B. (2008). Teknologi pembelajaran, landasan dan aplikasinya. Jakarta: Rineka Cipta

Wening, A. (2011). Pengembangan multimedia matematika interaktif untuk meningkatkan kemampuan berpikir kritis dan kreatif siswa $s d$. Tesis PPs UPI. Bandung. Tidak dipublikasikan

Winarno. (2012). Pembuatan media pembelajaran interaktif elektronika dasar pada sekolah menengah kejuruan teknik elektronika audio video Journal Speed - Sentra Penelitian Engineering dan Edukasi Volume 4 No 3, hlm 25-31

Wulandari, F.R.A, Dewi, N.R, \& Akhlis, I. (2013). Pengembangan cd interaktif pembelajaran ipa terpadu tema energi dalam kehidupan untuk siswa smp. Unees science educational journal 2 (2), hlm 262-268 